Pacific Journal of Mathematics

CONTINUOUS OPERATORS ON PARANORMED SPACES AND 


\title{
CONTINUOUS OPERATORS ON PARANORMED SPACES AND MATRIX TRANSFORMATIONS
}

\author{
Ivor J. Maddox and Michael A. L. Willey
}

The concept of a paranormed $\beta$-space is defined and some theorems of Banach-Steinhaus type are proved for sequences of continuous linear functionals on such a space. For example, necessary and sufficient conditions are given for a sequence $\left(A_{n}(x)\right)$ of continuous linear functionals to be in the space of generalized entire sequences, for each $x$ belonging to a paranormed $\beta$-space. The general theorems are then used to characterize matrix transformations between generalized $l_{p}$ spaces and generalized entire sequences.

1. In $\S 2$ we present theorems which generalize some results in [10]. These theorems are applied in $\S 3$ to characterize some classes of matrix transformations. By $N, R$ and $C$ we denote respectively, the sets of natural numbers, real numbers, and complex numbers. By a sequence $\left(x_{k}\right)$ we mean $\left(x_{1}, x_{2}, \cdots\right)$, and by $\Sigma_{k} x_{k}$ we mean $\sum_{k=1}^{\infty} x_{k}$.

$X$ will denote a nontrivial complex linear space of elements $x$, with zero element $\theta$ and with paranorm $g$, i.e. $g: X \rightarrow R$ satisfies $g(\theta)=0, g(x)=g(-x)$ on $X, g$ is subadditive, and, for $\lambda \in C$ and $x \in X$, $\lambda \rightarrow \lambda_{0}$ and $g\left(x-x_{0}\right) \rightarrow 0$ imply $g\left(\lambda_{2} x-\lambda_{0} x_{0}\right) \rightarrow 0$, where $\lambda_{0} \in C$ and $x_{0} \in X$.

Extending the definitions of Sargent in [8], we can define a paranormed $\beta$-space as follows. Let $\left(X_{n}\right)$ be a sequence of subsets of $X$ such that $\theta \in X_{1}$ and such that if $x, y \in X_{n}$ then $x \pm y \in X_{n+1}$ for $n \in N$; then $\left(X_{n}\right)$ is called an $\alpha$-sequence in $X$. If we can write $X=\bigcup_{n=1}^{\infty} X_{n}$, where $\left(X_{n}\right)$ is an $\alpha$-sequence in $X$ and each $X_{n}$ is nowhere dense in $X$, then $X$ is called an $\alpha$-space; otherwise $X$ is a $\beta$-space. Clearly, every $\alpha$-space is of the first category, whence we see that any complete paranormed space is a $\beta$-space.

If $Y \subset X$ then we denote the closure of $Y$ in $X$ by $\bar{Y}$. We write, for any $a \in X$ and $\delta>0, S(\alpha, \delta)=\{x: x \in X$ and $g(x-a)<\delta\} . \quad A$ subset $G$ of $X$ is called a fundamental set in $X$ if $l$. hull $(G)$, the set of all finite linear combinations of elements of $G$, is dense in $X$. A sequence $\left(b_{k}\right)$ of elements of $X$ is said to be a basis in $X$ if for each $x \in X$ there is a unique complex sequence $\left(\lambda_{k}\right)$ such that $g\left(x-\sum_{k=1}^{n} \lambda_{k} b_{k}\right) \rightarrow 0(n \rightarrow \infty)$. Thus any basis in $X$ is also a fundamental set in $X$.

We denote the set of continuous linear functionals on $X$ by $X^{*}$. A linear functional $A$ on $X$ is an element of $X^{*}$ if and only if 


$$
\|A\|_{M} \equiv \sup \left\{|A(x)|: g(x) \leqq \frac{1}{M}\right\}<\infty \text { for some } M>1 .
$$

If $X$ is a space of complex sequences $x=\left(x_{k}\right)$, then we denote the generalized Köthe-Toeplitz dual of $X$ by $X^{\dagger}$, i.e.

$$
X^{\dagger}=\left\{\left(\alpha_{k}\right): \Sigma_{k} \alpha_{k} x_{k} \text { converges for every } x \in X\right\} .
$$

We now list some sets of complex sequences due to Maddox [4]. If $p=\left(p_{k}\right)$ is a sequence of strictly positive real numbers, then

$$
\begin{gathered}
l_{\infty}(p)=\left\{x: \sup _{k}\left|x_{k}\right|^{p_{k}}<\infty\right\}, \\
c_{0}(p)=\left\{x: \lim _{k}\left|x_{k}\right|^{p_{k}}=0\right\}, \\
c(p)=\left\{x: \lim _{k}\left|x_{k}-l\right|^{p_{k}}=0 \text { for some } l \in C\right\}, \\
l(p)=\left\{x: \Sigma_{k}\left|x_{k}\right|^{p_{k}}<\infty\right\} .
\end{gathered}
$$

We write $e^{(k)}=(0,0, \cdots, 1,0,0, \cdots)$, the 1 occurring in the $k^{\text {th }}$ place, for each $k \in N$, and $e=(1,1,1, \cdots)$, and we write $l_{\infty}=l_{\infty}(e), c_{0}=c_{0}(e)$, $c=c(e)$, and $l_{1}=l(e)$.

The case $p=(1 / k)$ of $c_{0}(p)$ is of particular interest, since the function defined by $\sum_{k=0}^{\infty} \alpha_{k} z^{k}, z \in C$, is an entire function if and only if $\left(\alpha_{k}\right) \in c_{0}(1 / k)$. Work on the space of entire functions has been carried out, by V. Ganapathy Iyer in [2] and in other papers, and by other authors, using this correspondence with $c_{0}(1 / k)$. It is shown in [2] that $c_{0}(1 / k)^{\dagger}=l_{\infty}(1 / k)$.

Now we collect some known results which will be useful in what follows.

Lemma 1. $l(p)$ is a linear space if and only if $p$ is bounded. (See [4], Theorem 1, and [7], Theorem 1.)

Lemma 2. If $p$ is bounded with $H=\max \left(\sup p_{k}, 1\right)$, then $g(x)=\left(\Sigma_{k}\left|x_{k}\right|^{p_{k}}\right)^{1 / H}$ defines a paranorm on $l(p), l(p)$ is complete under $g$, and $\left(e^{(k)}\right)$ is a basis in $l(p)$. (See [5], Theorem 1 and Corollary 1, and [7].)

Lemma 3. (i) If $1<p_{k} \leqq H$ and $p_{k}^{-1}+s_{k}^{-1}=1$ for each $k \in N$, then

$$
l(p)^{\dagger}=\left\{\left(\alpha_{k}\right): \Sigma_{k}\left|\alpha_{k}\right|^{s_{k}} \cdot M^{-s_{k}}<\infty \text { for some } M>1\right\} .
$$

(ii) If $0<p_{k} \leqq 1$ for all $k \in N$ then $l(p)^{\dagger}=l_{\infty}(p)$.

(See [6], Theorem 1, and [9], Theorem 7.)

LEMma 4. If either $1<p_{k} \leqq H$ for all $k$, or $0<p_{k} \leqq 1$ for all 
$k$, then every $A \in l(p)^{*}$ may be written as $A(x) \equiv \Sigma_{k} \alpha_{k} x_{k}$ on $l(p)$ for some $\left(\alpha_{k}\right) \in l(p)^{\dagger}$, and conversely $A(x) \equiv \Sigma_{k} \alpha_{k} x_{k}$ defines an element of $l(p)^{*}$ for each $\left(\alpha_{k}\right) \in l(p)^{\dagger}$. (See [6], Theorem 2, and [9], Theorem 7.)

Given sets $Y$ and $Z$ of sequences and a matrix $A=\left(a_{n, k}\right)$ of complex numbers $(n, k=1,2, \cdots)$ we say that $A \in(Y, Z)$ if and only if $\Sigma_{k} a_{n, k} y_{k}$ converges for every $y=\left(y_{k}\right) \in Y$ and $n \in N$, and $\left(\Sigma_{k} a_{n, k} y_{k}\right) \in Z$ for every $y \in Y$.

We shall frequently use the following inequalities. Take $x, y \in C$; if $0<p \leqq 1$ then

$$
|x|^{p}-|y|^{p} \leqq|x+y|^{p} \leqq|x|^{p}+|y|^{p},
$$

and if $p>1$ and $p^{-1}+s^{-1}=1$ then

$$
|x y| \leqq|x|^{p}+|y|^{s} \text {. }
$$

2. For the remainder of this paper, $q=\left(q_{n}\right)$ will denote a sequence of strictly positive real numbers. If $q$ is bounded with $H=\max \left(\sup q_{n}, 1\right)$ then it follows by Lemma 1 of [4] that $c_{0}(q)=$ $c_{0}\left(H^{-1} q\right)$; similarly $l_{\infty}(q)=l_{\infty}\left(H^{-1} q\right)$ and $c(q)=c\left(H^{-1} q\right)$.

THEOREM 1. Let $X$ be a paranormed space and let $\left(A_{n}\right)$ be a sequence of elements of $X^{*}$, and suppose $q$ is bounded. Then

$$
\sup _{n}\left(\left\|A_{n}\right\|_{M}\right)^{q_{n}}<\infty \text { for some } M>1
$$

implies

$$
\left(A_{n}(x)\right) \in l_{\infty}(q) \text { for every } x \in X,
$$

and the converse is true if $X$ is a $\beta$-space.

Proof. In view of the remarks at the beginning of this section, we may without loss of generality assume that $q_{n} \leqq 1$ fore all $n \in N$. First let (1) hold, and choose any $x \in X$. By the continuity of scalar multiplication in a paranormed space, there is a $K \geqq 1$ such that $g\left(K^{-1} x\right) \leqq 1 / M$, where the $M$ is that of (1). Then we have for any $n$, since $q_{n} \leqq 1$,

$$
\begin{aligned}
\left|A_{n}(x)\right|^{q_{n}} & =\left|K A_{n}\left(K^{-1} x\right)\right|^{q_{n}} \leqq K^{q_{n}}\left(\left\|A_{n}\right\|_{M}\right)^{q_{n}} \\
& \leqq K \sup _{n}\left(\left\|A_{n}\right\|_{M}\right)^{q_{n}}
\end{aligned}
$$

so that (2) holds.

Now let (2) hold, with $X$ a $\beta$-space, and define for any $m \in N$,

$$
X_{m}=\left\{x: x \in X \text { and }\left|A_{n}(x)\right|^{q_{n}} \leqq 2^{m} \text { for all } n \in N\right\} .
$$

Then $\left(X_{m}\right)$ is an $\alpha$-sequence in $X$, for obviously $\theta \in X_{1}$, and if for 
some $m \geqq 1, x, y \in X_{m}$ then, since $q_{n} \leqq 1$ for every $n$,

$$
\left|A_{n}(x \pm y)\right|^{q_{n}} \leqq\left|A_{n}(x)\right|^{q_{n}}+\left|A_{n}(y)\right|^{q_{n}} \leqq 2^{m+1}
$$

for any $n \in N$. Also $X=\bigcup_{m=1}^{\infty} X_{m}$, so since $X$ is a $\beta$-space there exists a $B \in N$ such that $X_{B}$ is not nowhere dense. Using the continuity of the $A_{n}$, it is not difficult to show that $\bar{X}_{m}=X_{m}$ for every $m$, whence there is a sphere $S(a, \delta) \subset X_{B}$. Thus if $g(x-a)<\delta$ we have $\left|A_{n}(x)\right|^{q_{n}} \leqq 2^{B}$ for all $n$, so if $g(x)<\delta$ we have

$$
\left|A_{n}(x)\right|^{q_{n}} \leqq\left|A_{n}(x+a)\right|^{q_{n}}+\left|A_{n}(a)\right|^{q_{n}} \leqq 2^{B+1} \text { for all } n \text {. }
$$

Taking $M>\delta^{-1}$ we obtain (1).

THEOREM 2. Let $X$ be a paranormed space and let $\left(A_{n}\right)$ be a sequence of elements of $X^{*}$.

(i) If $X$ has fundamental set $G$ and if $q$ is bounded, then the following propositions

$$
\left(A_{n}(b)\right) \in c_{0}(q) \text { for every } b \in G,
$$

$$
\lim _{M} \lim \sup _{n}\left(\left\|A_{n}\right\|_{M}\right)^{q_{n}}=0 \text {, }
$$

together imply

$$
\left(A_{n}(x)\right) \in c_{0}(q) \text { for every } x \in X .
$$

(ii) If $q_{n} \rightarrow 0(n \rightarrow \infty)$ then (4) implies (5).

(iii) Let $X$ be a $\beta$-space; then (5) implies (4) even if $q$ is unbounded.

Proof. (i) Again, we may without loss of generality assume that $q_{n} \leqq 1$ for every $n \in N$. Let $X$ have fundamental set $G$, and suppose (3) and (4) hold. Choose any $x \in X$ and any $\varepsilon>0$. There exist $M>1$ and $n_{0}$ such that $\left(\left\|A_{n}\right\|_{M}\right)^{q_{n}}<\varepsilon / 2$ for all $n \geqq n_{0}$, by (4). Since $l \cdot$ hull $(G)$ is dense in $X$ there exist $\lambda_{1}, \lambda_{2}, \cdots, \lambda_{m} \in C$ and $b_{1}, b_{2}, \cdots, b_{m} \in G$ such that $g\left(x-\sum_{k=1}^{m} \lambda_{k} b_{k}\right)<1 / M$, and we write $L=$ $\max \left(\left|\lambda_{1}\right|, \cdots,\left|\lambda_{m}\right|, 1\right)$. Then by (3) there is an $n_{1} \geqq n_{0}$ such that $\left|A_{n}\left(b_{k}\right)\right|^{q_{n}}<\varepsilon /(2 L m), k=1,2, \cdots, m$, if $n \geqq n_{1}$, whence if $n \geqq n_{1}$, we have

$$
\begin{aligned}
\left|A_{n}(x)\right|^{q_{n}} & =\left|A_{n}\left(x-\sum_{k=1}^{m} \lambda_{k} b_{k}\right)+\sum_{k=1}^{m} \lambda_{k} A_{n}\left(b_{k}\right)\right|^{q_{n}} \\
& \leqq \mid A_{n}\left(x-\left.\sum_{k=1}^{m} \lambda_{k} b_{k}\right|^{q_{n}}+L \sum_{k=1}^{m}\left|A_{n}\left(b_{k}\right)\right|^{q_{n}}\right. \\
& \leqq\left(\left\|A_{n}\right\|_{M}\right)^{q_{n}}+m L \cdot \varepsilon /(2 L m)<\varepsilon ;
\end{aligned}
$$

thus (5) holds. 
(ii) Suppose (4) holds and $q \in c_{0}$, and choose any $x \in X$ and any $\varepsilon>0$. There is an $M>1$ and an $n_{0}$ such that $\left(\left\|A_{n}\right\|_{M}\right)^{q_{n}}<\varepsilon / 2$ if $n \geqq n_{0}$, and since scalar multiplication is continuous on $X$ there is a $K \geqq 1$ such that $g\left(K^{-1} x\right) \leqq 1 / M$. Then we can choose $n_{1} \geqq n_{0}$ such that $K^{q_{n}} \leqq 2$ if $n \geqq n_{1}$ whence if $n \geqq n_{1}$

$$
\left|A_{n}(x)\right|^{q_{n}}=K^{q_{n}}\left|A_{n}\left(K^{-1} x\right)\right|^{q_{n}}<\varepsilon,
$$

so that (5) is true.

(iii) Let $X$ be a $\beta$-space and suppose (5) is true. We define sequences $\left(B_{n}\right),\left(C_{n}\right)$ of elements of $X^{*}$ and sequences $r=\left(r_{n}\right), s=\left(s_{n}\right)$ of strictly positive real numbers as follows. If $q_{n} \geqq 1$ then define $B_{n}=A_{n}, C_{n}=0, r_{n}=q_{n}$, and $s_{n}=1$; if $q_{n}<1$ write $B_{n}=0, C_{n}=A_{n}$, $r_{n}=1$, and $s_{n}=q_{n}$. Then $\left(B_{n}(x)\right) \in c_{0}(r)$ and $\left(C_{n}(x)\right) \in c_{0}(s)$ on $X$; $\sup _{n} s_{n} \leqq 1$, and $r_{n} \geqq 1$ for all $n \in N$. Also, $\left(\left\|A_{n}\right\|_{M}\right)^{q_{n}}=\left(\left\|B_{n}\right\|_{M}\right)^{r_{n}}+$ $\left(\left\|C_{n}\right\|_{M}\right)^{s_{n}}$ for all large enough $M, n=1,2, \cdots$, whence

$$
\begin{aligned}
\lim _{M} \lim \sup _{n}\left(\left\|A_{n}\right\|_{M}\right)^{q_{n}} \leqq & \lim _{M} \lim \sup _{n}\left(\left\|B_{n}\right\|_{M}\right)^{r_{n}} \\
& +\lim _{M} \lim \sup _{n}\left(\left\|C_{n}\right\|_{M}\right)^{s_{n}} .
\end{aligned}
$$

Choose any $\varepsilon>0$, and define for each $m \in N$

$$
X_{m}=\left\{x: x \in X \text { and }\left|2^{-m} C_{n}(x)\right|^{s_{n}} \leqq \frac{\varepsilon}{2} \text { for all } n \geqq m\right\} .
$$

Clearly $\theta \in X_{1}$, and if for some $m \in N$ we have $x, y \in X_{m}$ then for $n \geqq m+1$

$$
\begin{aligned}
\left|2^{-(m+1)} C_{n}(x \pm y)\right|^{s_{n}} & \leqq\left(\left|2^{-(m+1)} C_{n}(x)\right|+\left|2^{-(m+1)} C_{n}(y)\right|\right)^{s_{n}} \\
& \leqq\left(2 \max \left(\left|2^{-(m+1)} C_{n}(x)\right|,\left|2^{-(m+1)} C_{n}(y)\right|\right)\right)^{s_{n}} \\
& =\max \left(\left|2^{-m} C_{n}(x)\right|^{s_{n}},\left|2^{-m} C_{n}(y)\right|^{s_{n}}\right) \leqq \frac{\varepsilon}{2} ;
\end{aligned}
$$

thus $\left(X_{m}\right)$ is an $\alpha$-sequence in $X$. Also $X=\bigcup_{m=1}^{\infty} X_{m}$ and $X_{m}=\bar{X}_{m}$ for all $m \in N$ whence, since $X$ is a $\beta$-space, some $X_{B}$ contains a sphere $S(a, \delta)$. Then if $g(x)<\delta$ we deduce that $\left|2^{-B} C_{n}(x)\right|^{s_{n}} \leqq \varepsilon$ for $n \geqq B$. Write $\rho=2^{-B} \delta$ and choose $M>\rho^{-1}$; then by the subadditivity of $g$ we have $g\left(2^{B} x\right)<\delta$ if $g(x)<\rho$. Hence if $g(x) \leqq 1 / M$ we have

$$
\left|C_{n}(x)\right|^{s_{n}}=\left|2^{-B} C_{n}\left(2^{B} x\right)\right|^{s_{n}} \leqq \varepsilon \text { if } n \geqq B,
$$

and since $\varepsilon>0$ was arbitrary we obtain $\lim _{M} \lim \sup _{n}\left(\left\|C_{n}\right\|_{M}\right)^{s_{n}}=0$.

Now $\left(B_{n}(x)\right) \in c_{0}(r)$ on $X$ implies $\left(B_{n}(x)\right) \in c_{0}$ on $X$. For suppose if possible that for some sequence $(n(i))$ of integers and some $x \in X$ inf $\left|B_{n(i)}(x)\right|=\alpha>0$; then $\left|B_{n(i)}\left(\alpha^{-1} x\right)\right|^{r_{n}(i)} \geqq 1$ for all $i$, contrary to hypothesis. By the argument used above we deduce that

$$
\lim _{M} \lim \sup _{n}\left\|B_{n}\right\|_{M}=0
$$


whence since $r_{n} \geqq 1$ for all $n, \lim _{M} \lim \sup _{n}\left(\left\|B_{n}\right\|_{M}\right)^{r_{n}}=0$. By our earlier remarks, (4) now follows.

THEOREM 3. Let $X$ be a paranormed space and let $\left(A_{n}\right)$ be a sequence of element of $X^{*}$ and suppose $q$ is bounded.

(i) If $X$ has fundamental set $G$, and if there is an $l \in X^{*}$ such that $\left(A_{n}(b)-l(b)\right) \in c_{0}(q)$ for all $b \in G$ and

$$
\lim _{M} \lim \sup _{n}\left(\left\|A_{n}-l\right\|_{M}\right)^{q_{n}}=0,
$$

then

$$
\left(A_{n}(x)\right) \in c(q) \text { on } X \text {. }
$$

(ii) If $q_{n} \rightarrow 0(n \rightarrow \infty)$ and if there is an $l \in X^{*}$ such that (6) holds, then (7) is true.

(iii) If $X$ is a $\beta$-space and if (7) is true, then there is an $l \in X^{*}$ such that (6) holds.

Proof. ( i ) If the hypotheses hold, then $A_{n}-l \in X^{*}$ for every $n \in N$ whence by part (i) of Theorem $2\left(\left(A_{n}-l\right)(x)\right) \in c_{0}(q)$ on $X$; thus (7) is true.

(ii) Follows similarly from Theorem 2(ii).

(iii) Suppose (7) holds; then for some $l$ we have $\mid A_{n}(x)-$ $\left.l(x)\right|^{q} \rightarrow 0(n \rightarrow \infty)$ on $X$. We deduce that $l(x)=\lim _{n} A_{n}(x)$ on $X$ and $\sup _{n}\left|A_{n}(x)\right|<\infty$ on $X$. Then by Theorem 1 we have $\sup _{n}\left\|A_{n}\right\|_{M}<\infty$ for some $M>1$, whence $\|l\|_{M}<\infty$. Clearly $l$ must be linear, so that $l \in X^{*}$. Thus $A_{n}-l \in X^{*}$ for each $n \in N$, and by hypothesis $\left(\left(A_{n}-l\right)(x)\right) \in c_{0}(q)$ on $X$, so by Theorem 2(iii), (6) must be true.

3. We now apply the theorems above in characterizing the classes $\left(l(p), l_{\infty}(q)\right),\left(l(p), c_{0}(q)\right)$, and $(l(p), c(q))$ in the case when both $p$ and $q$ are bounded. Throughout, $A=\left(a_{n, k}\right)$ will denote an infinite matrix of complex numbers. As a preliminary, we state Theorem 1 of [3]:

Theorem 4. (i) Let $1<p_{k} \leqq H<\infty$ and $p_{k}^{-1}+s_{k}^{-1}=1$ for every $k$. Then $A \in\left(l(p), l_{\infty}\right)$ if and only if there exists an integer $B>1$ such that $\sup _{n} \Sigma_{k}\left|a_{n, k}\right|^{s_{k}} \cdot B^{-s_{k}}<\infty$.

(ii) Let $0<p_{k} \leqq 1$ for every $k$. Then $A \in\left(l(p), l_{\infty}\right)$ if and only if $\sup _{n, k}\left|a_{n, k}\right|^{p_{k}}<\infty$.

In the proofs of the following results, as in earlier ones, we may without loss of generality assume that $q_{n} \leqq 1$ for all $n \in N$, and we shall do so when convenient.

We first consider the case when $0<p_{k} \leqq 1$ for all $k \in N$. 
TheOREM 5. Suppose $0<p_{k} \leqq 1$ for all $k \in N$, and $q=\left(q_{n}\right)$ is bounded. Then,

(i ) $A \in\left(l(p), l_{\infty}(q)\right)$ if and only if

(8) $\sup _{n}\left(\sup _{k}\left|a_{n, k}\right| M^{-1 / p_{k}}\right)^{q_{n}}<\infty$ for some $M>1$.

(ii) $A \in\left(l(p), c_{0}(q)\right)$ if and only if

$$
\left|a_{n, k}\right|^{q_{n}} \rightarrow 0(n \rightarrow \infty) \text { for every } k \in N
$$

and

$$
\lim _{M} \lim \sup _{n}\left(\sup _{k}\left|a_{n, k}\right| M^{-1 / p_{k}}\right)^{q_{n}}=0 .
$$

(iii) $A \in(l(p), c(q))$ if and only if $\sup _{n} \sup _{k}\left|a_{n, k}\right| M^{-1 / p_{k}}<\infty$ for some $M>1$ and there exist $\alpha_{1}, \alpha_{2}, \ldots$ such that

$$
\left|a_{n, k}-\alpha_{k}\right|^{q_{n}} \rightarrow 0(n \rightarrow \infty) \text { for each } k \in N
$$

and

$$
\lim _{M} \lim \sup _{n}\left(\sup _{k}\left|a_{n, k}-\alpha_{k}\right| M^{-1 / p_{k}}\right)^{q_{n}}=0 .
$$

Proof. Write, for each $x \in l(p)$ and each $n \in N$

$$
A_{n}(x) \equiv \Sigma_{k} a_{n, k} x_{k} \text {. }
$$

(i) Let $A \in\left(l(p), l_{\infty}(q)\right)$; then for each $n,\left(a_{n, 1}, a_{n, 2}, \cdots\right) \in l(p)^{\dagger}=$ $l_{\infty}(p)$, by Lemma 3(ii). Also, by Lemma $4, A_{n} \in l(p)^{*}$ for each $n \in N$. We show that for each $n,\left\|A_{n}\right\|_{M}=\sup _{k}\left|a_{n, k}\right| M^{-1 / p_{k}}$ for all $M$ such that $\left\|A_{n}\right\|_{M}$ is defined. Choose any $n \in N$. First, if $M$ is such that, for some sequence $(k(i))$ of integers, $\left|a_{n, k(i)}\right| M^{-1 / p_{k(i)}} \geqq i$ for each $i \in N$, then by defining $x^{(k(i))}=\left(M^{\left.-1 / p_{k(i)}\right)} \operatorname{sgn} a_{n, k(i)}\right) e^{(k(i))}, i=1,2, \cdots$, we see that $\left\|A_{n}\right\|_{M}$ is undefined. Since $\left(a_{n, 1}, a_{n, 2}, \cdots\right) \in l_{\infty}(p)$ there is an $M_{n} \geqq 1$ such that $\left|a_{n, k}\right|^{p_{k}} \leqq M_{n}$ for all $k$. Choose $M \geqq M_{n}$. We have if $g(x)=\Sigma_{k}\left|x_{k}\right|^{p_{k}} \leqq 1 / M$, since $M^{1 / p_{k}}\left|x_{k}\right| \leqq 1$ for all $k$ and since $\sup _{k} p_{k} \leqq 1$,

$$
\begin{aligned}
\left|A_{n}(x)\right| & \leqq \Sigma_{k}\left|a_{n, k}\right| M^{-1 / p_{k}} \cdot M^{1 / p_{k}}\left|x_{k}\right| \\
& \leqq \Sigma_{k}\left|a_{n, k}\right| M^{-1 / p_{k}} \cdot M\left|x_{k}\right|^{p_{k}} \\
& \leqq M g(x) \sup _{k}\left|a_{n, k}\right| M^{-1 / p_{k}}
\end{aligned}
$$

whence $\left\|A_{n}\right\|_{M} \leqq \sup _{k}\left|a_{n, k}\right| M^{-1 / p_{k}}$. Given $\varepsilon>0$ we can choose an $m$ such that $\left|a_{n, m}\right| M^{-1 / p_{k}}>\sup _{k}\left|a_{n, k}\right| M^{-1 / p_{k}}-\varepsilon$. Defining $x=$ $\left(M^{-1 / p_{k}} \operatorname{sgn} a_{n, m}\right) e^{(m)}$ we have $g(x) \leqq 1 / M$ and $A_{n}(x)>\sup _{k}\left|a_{n, k}\right| M^{-1 / p_{k}}-\varepsilon$, whence $\left\|A_{n}\right\|_{M}=\sup _{k}\left|a_{n, k}\right| M^{-1 / p_{k}}$ as required. By Lemma $2, l(p)$ is complete, so it is a $\beta$-space; thus by Theorem 1 we must have (8).

Conversely let (8) hold. Then as above it follows that for each $n, A_{n} \in l(p)^{*}$ with $\left\|A_{n}\right\|_{M}=\sup _{k}\left|a_{n, k}\right| M^{-1 / p_{k}}$ for all $M$ such that 
$\left\|A_{n}\right\|_{M}$ is defined. Then using Theorem 1 we obtain $\left(A_{n}(x)\right) \in l_{\infty}(q)$ on $l(p)$, i.e. $A \in\left(l(p), l_{\infty}(q)\right)$.

We remark that (8) reduces to $\sup _{n, k}\left|a_{n, k}\right|^{p_{k}}<\infty$ if $0<\inf q_{n} \leqq$ $\sup q_{n}<\infty$, corresponding to the condition given for $A \in\left(l(p), l_{\infty}\right)$ in Theorem 4(ii).

(ii) If $A \in\left(l(p), c_{0}(q)\right) \subset\left(l(p), l_{\infty}(q)\right)$ then as above we have $A_{n} \in X^{*}$ and $\left\|A_{n}\right\|_{M}=\sup _{k}\left|a_{n, k}\right| M^{-1 / p_{k}}$ whenever $\left\|A_{n}\right\|_{M}$ is defined, for each $n \in N$. Then, by Theorem 2(iii), (10) must hold. Also taking $x=$ $e^{(k)} \in l(p)(k=1,2, \cdots)$ we obtain (9). Conversely if (9) and (10) hold we can show that $A_{n} \in l(p)^{*}$ with $\left\|A_{n}\right\|_{M}=\sup _{k}\left|a_{n, k}\right| M^{-1 / p_{k}}$ whenever $\left\|A_{n}\right\|_{M}$ is defined, for each $n \in N$; also $\left(e^{(k)}\right)$ is a basis in $l(p)$ by Lemma 2. Then by Theorem 2(i) we can deduce that $A \in\left(l(p), c_{0}(q)\right)$.

(iii) Let $A \in(l(p), c(q))$; then as in (i) and (ii) above we have for each $n$ that $A_{n} \in X^{*}$. By Theorem 3(iii) there is an $l \in X^{*}$ such that $\lim _{M} \lim \sup _{n}\left(\left\|A_{n}-l\right\|_{M}\right)^{q_{n}}=0$, and by Lemmas 3(ii) and 4 we can write $l(x)=\Sigma_{k} \alpha_{k} x_{k}$ on $l(p)$ for some $\left(\alpha_{k}\right) \in l_{\infty}(p)$. We deduce that $\left\|A_{n}-l\right\|_{M}=\sup _{k}\left|\alpha_{n, k}-\alpha_{k}\right| M^{-1 / p_{k}}$ for large enough $M, n=1,2 \cdots$, whence (12) is true, and (11) must hold since $\left(A_{n}-l\right)\left(e^{(k)}\right)=a_{n, k}-\alpha_{k}$ for each $n$ and $k$. Also $c(q) \subset l_{\infty}$ whence $\left(l(p),(c(q)) \subset\left(l(p), l_{\infty}\right)\right.$; thus by (i) we must have $\sup _{k}\left|a_{n, k}\right| M^{-1 / p_{k}}<\infty$ for some $M>1$.

Finally, if $\sup _{k}\left|a_{n, k}\right| M^{-1 / k_{k}}<\infty$ for some $M>1$ then $A_{n} \in l(p)^{*}$ for all $n$. If in addition (11) and (12) hold then for any $k$ we have, if $n$ and $M$ are large enough,

$$
\begin{aligned}
\left|\alpha_{k}\right| M^{-1 / p_{k}} & \leqq\left|a_{k}-a_{n, k}\right| M^{-1 / p_{k}}+\left|a_{n, k}\right| M^{-1 / p_{k}} \\
& \leqq 1+\sup _{n}\left(\sup _{k}\left|a_{n, k}\right| M^{-1 / p_{k}}\right)=B \text { say }
\end{aligned}
$$

hence $\left|\alpha_{k}\right|^{p_{k}} \leqq B^{p_{k}} \cdot M \leqq B M$ for all $k$, i.e. $\left(\alpha_{k}\right) \in l_{\infty}(p)=l(p)^{\dagger}$. By Lemma $4, l(x) \equiv \Sigma_{k} \alpha_{k} x_{k}$ defines an element of $l(p)^{*}$, and the result now follows if we employ the methods used above together with Theorem 3(i).

THEOREM 6. Suppose $0<p_{k} \leqq 1$ for all $k \in N$ and $q_{n} \rightarrow 0(n \rightarrow \infty)$. Then $\left.A \in l(p), c_{0}(q)\right)$ if and only if (12) is true.

Proof. This follows from Theorem 2, parts (ii) and (iii), on using the methods of Theorem 5 .

Corollary. (i ) $A \in\left(l_{1}, c_{0}(1 / n)\right)$ if and only if $\left|a_{n, k}\right|^{1 / n} \rightarrow 0$ uniformly in $k$ as $n \rightarrow \infty$.

(ii) $A \in\left(l_{1}, l_{\infty}(1 / n)\right)$ if and only if $\sup _{n, k}\left|a_{n, k}\right|^{1 / n}<\infty$.

Proof. These characterizations were given in Theorems 1 and 2 of [1], and follow readily on taking $p=e$ and $q=(1 / n)$ in Theorems $5(\mathrm{i})$ and 6. 
Now we consider the case when $1<p_{k} \leqq H<\infty$ for all $k$.

THEOREM 7. Let $1<p_{k} \leqq H$ and $p_{k}^{-1}+s_{k}^{-1}=1$ for each $k \in N$, and let $q$ be bounded. Then $A \in\left(l(p), l_{\infty}(q)\right)$ if and only if

$$
T(B) \equiv \sup _{n} \Sigma_{k}\left|a_{n, k}\right|^{s_{k}} \cdot B^{-s_{k} / q_{n}}<\infty \text { for some } B>1 \text {. }
$$

Proof. Define $A_{n}$ by (13) on $l(p)$, for each $n \in N$. For the sufficiency, let (14) hold. Then if $x \in l(p)$ we have for each $n$, assuming $q_{n} \leqq 1$ for all $n$,

$$
\begin{aligned}
\left|A_{n}(x)\right|^{q_{n}} & \leqq\left(\Sigma_{k}\left|a_{n, k} x_{k}\right|\right)^{q_{n}}=\left(\Sigma_{k}\left|a_{n, k}\right| B^{-1 / q_{n}} \cdot B^{1 / q_{n}}\left|x_{k}\right|\right)^{q_{n}} \\
& \leqq\left(\Sigma_{k}\left|a_{n, k}\right|^{s_{k}} \cdot B^{-s_{k} / q_{n}}+\Sigma_{k} B^{p_{k} / q_{n}}\left|x_{k}\right|^{p_{k}}\right)^{q_{n}} \\
& \leqq(T(B))^{q_{n}}+B^{H}\left(g^{H}(x)\right)^{q_{n}} \\
& \leqq T(B)+1+B^{H}\left(g^{H}(x)+1\right)
\end{aligned}
$$

which implies $A \in\left(l(p), l_{\infty}(q)\right)$.

Now let $A \in\left(l(p), l_{\infty}(q)\right)$; then $\left(a_{n, 1}, a_{n, 2}, \cdots\right) \in l(p)^{\dagger}$ for each $n$ and so, by Lemmas $3(\mathrm{i})$ and $4, A_{n} \in l(p)$ for all $n$. By Theorem 1 there exist $M>1$ and $G \geqq 1$ such that $\left|A_{n}(x)\right|^{q_{n}} \leqq G$ for all $n$ and all $x \in l(p)$ with $g(x) \leqq 1 / M$. Then $\left|\Sigma_{k} G^{-1 / q_{n}} \cdot a_{n, k} x_{k}\right| \leqq 1, n=1,2, \cdots$, if $g(x) \leqq 1 / M$. Write $\Gamma=\left(G^{-1 / q_{n}} a_{n, k}\right)$, and choose any $x \in l(p)$. By the continuity of scalar multiplication on $l(p)$ there is a $K \geqq 1$ such that $g\left(K^{-1} x\right) \leqq 1 / M$, whence $\left|\Sigma_{k} G^{-1 / q_{n}} \cdot a_{n, k} x_{k}\right| \leqq K$ for all $n$. Thus we see that $\Gamma \in\left(l(p), l_{\infty}\right)$ and so by Theorem 4(i) there is a $D>1$ such that $\sup _{n} \Sigma_{k}\left|G^{-1 / q_{n}} \cdot a_{n, k}\right|^{s_{k}} \cdot D^{-s_{k}}<\infty$. Writing $B=G D$ and using the fact that $D^{q} \leqq D$ for all $n$, we obtain (14).

Looking at Theorem 4, one might except the necessary and sufficient condition for $A \in\left(l(p), l_{\infty}(q)\right)$ to be

$$
\sup _{n}\left(\sum_{k}\left|a_{n, k}\right|^{s_{k}} \cdot M^{-s_{k}}\right)^{q_{n}}<\infty \text { for some } M>1 .
$$

Using the method above we can show that (15) implies $A \in$ $\left(l(p), l_{\infty}(q)\right)$. In fact it can be shown that (15) implies (14) directly. For let (15) hold; then for some $B>1,\left(\Sigma_{k}\left|a_{n, k}\right|^{s_{k}} \cdot B^{-s_{k}}\right)^{q_{n}} \leqq H$ for all $n$, and we may suppose that $H>1$. If $q_{n} \leqq Q$ for all $n$ then

$$
\left(\Sigma_{k}\left|a_{n, k}\right|^{s_{k}} \cdot B^{-s_{k}} \cdot H^{-1 / q_{n}}\right)^{q_{n} / Q} \leqq 1 \text { for all } n \text {. }
$$

Put $M=H B^{Q}$; then $M^{s_{k}}=H^{s_{k}} \cdot B^{s_{s_{k}}} \geqq H \cdot B^{q_{n} s_{k}}$, whence $M^{s_{k} / q_{n}} \geqq H^{1 / q_{n}} \cdot B^{s_{k}}$ for all $k$ and $n$. Thus by (16) we obtain

$$
\begin{aligned}
\Sigma_{k}\left|a_{n, k}\right|^{s_{k}} \cdot M^{-s_{k} / q_{n}} & \leqq \Sigma_{k}\left|a_{n, k}\right|^{s_{k}} \cdot B^{-s_{k}} \cdot H^{-1 / q_{n}} \\
& \leqq\left(\Sigma_{k}\left|a_{n, k}\right|^{s_{k}} \cdot B^{-s_{k}} \cdot H^{-1 / q_{n}}\right)^{q_{n} / q} \leqq 1 \text { for all } n,
\end{aligned}
$$

whence $T(M) \leqq 1$, i.e. (14) holds. 
Clearly, (14) implies (15) if $\inf _{n} q_{n}>0$ or if $\inf _{k} p_{k}>1$. However, (15) is not necessary for $A \in\left(l(p), l_{\infty}(q)\right)$ if $\inf _{n} q_{n}=0$ and $\inf _{k} p_{k}=1$. For choose bounded $p$ and $q$, with $p_{k}>1$ for all $k$, and suppose there exist sequence $(n(i),(k(j))$ of integers such that $q_{n(i)} \leqq 1 / i, i=1,2 \cdots$, and $p_{k(j)} \leqq 1+1 / j, j=1,2, \cdots ;$ then $s_{k(j)} \geqq$ $j+1$ for each $j$. Define $a_{n(i), k(j)}=i, i, j=1,2, \cdots$, and $a_{n, k}=0$ for all other $n$ and $k$. Then $A=\left(a_{n, k}\right) \in\left(l(p), l_{\infty}(q)\right)$ since for all $i \in N$.

$$
\Sigma_{j}\left|a_{n(i), k(j)}\right|^{s_{k(j)}} \cdot 2^{-s_{k(j)} / q_{n(i)}} \leqq \Sigma_{j}\left(i / 2^{i}\right)^{j+1} \leqq 1,
$$

but for any $M>1$ we have if $i \geqq M$,

$$
\left(\Sigma_{j}\left|a_{n(i), k(j)}\right|^{s_{k(j)}} \cdot M^{-s_{k(j)}}\right)^{q_{n(i)}} \geqq\left(\Sigma_{j}|i / M|^{j+1}\right)^{q_{n(i)}},
$$

which diverges.

TheOREM 8. Let $q$ be bounded, and let $1<p_{k} \leqq H$ and $p_{k}^{-1}+$ $s_{k}^{-1}=1$ for all $k \in N$. Then $A \in\left(l(p), c_{0}(q)\right)$ if and only if (9) holds and, for every $D \geqq 1$,

$$
\lim _{B} \lim \sup _{n}\left(\Sigma_{k}\left|a_{n, k}\right|^{s_{k}} \cdot D^{s_{k} / q_{n}} \cdot B^{-s_{k}}\right)^{q_{n}}=0 .
$$

Proof. Again, define $A_{n}$ on $l(p)$ by (13). First we prove the necessity: let $A \in\left(l(p), c_{0}(q)\right)$. Obviously we must have (9), and as in Theorem 7 we see that $A_{n} \in l(p)^{*}$ for all $n$. If $A \in\left(l(p), c_{0}(q)\right)$ then $\left(D^{1 / q_{n}} \cdot a_{n, k}\right) \in\left(l(p), c_{0}(q)\right)$ for all $D>1$, so it is enough to show that (17) holds for $D=1$. Since $c_{0}(q) \subset l_{\infty}$ and using Theorem 4(i) there is a $B>1$ such that $T_{n} \equiv \Sigma_{k}\left|a_{n, k}\right|^{s_{k}} \cdot B^{-H s_{k}} \leqq 1$ for every $n \in N$. Choose any $n$, and define $x_{k}^{(n)}=B^{-H s_{k}}\left|a_{n, k}\right|^{s_{k}-1} \operatorname{sgn} a_{n, k}$ for each $k$; then

$$
g^{H}\left(x^{(n)}\right)=\Sigma_{k} B^{-H s_{k}-H p_{k}}\left|a_{n . k}\right|^{s k} \leqq B^{-H} T_{n} \leqq B^{-H}
$$

and $A_{n}\left(x^{(n)}\right)=T_{n}$, whence $\left\|A_{n}\right\|_{B} \geqq T_{n}$ for each $n$. By Theorem 2(iii) we must have $\lim _{B} \lim \sup _{n}\left(\left\|A_{n}\right\|_{B}\right)^{g_{n}}=0$, whence (17) holds with $D=1$.

For the sufficiency, let (9) be true and let (17) hold for all $D \geqq 1$. It follows that $A_{n} \in l(p)^{*}$ for all $n \in N$. Since $\left(e^{(k)}\right)$ is a basis in $l(p)$ and using Theorem 2(i) it is enough to show that $\lim _{B} \lim \sup _{n}\left(\left\|A_{n}\right\|_{B}\right)^{q_{n}}=0$. Choose $\varepsilon, 0<\varepsilon \leqq 1$, and $D>2 / \varepsilon$. There exist $B>1$ and $m$ such that $\left(\Sigma_{k}\left|a_{n, k}\right|^{s_{k}} \cdot D^{s_{k} / q_{n}} \cdot B^{-s_{k}}\right)^{q_{n}}<\varepsilon / 2$ if $n \geqq m$. Then if $g(x) \leqq 1 / B$ and if $n \geqq m$ we have

$$
\begin{aligned}
\left|A_{n}(x)\right|^{q_{n}} & \leqq\left(\Sigma_{k}\left|a_{n, k}\right| D^{1 / q_{n}} \cdot B^{-1} \cdot B D^{-1 / q_{n}}\left|x_{k}\right|\right)^{q_{n}} \\
& \leqq\left(\Sigma_{k}\left\{\left|a_{n, k}\right|^{s_{k}} D \cdot{ }^{s_{k} / q_{n}} \cdot B^{-s_{k}}+D^{-p_{k} / q_{n}} \cdot B^{p_{k}}\left|x_{k}\right|{ }^{p_{k}}\right\}\right)^{q_{n}} \\
& <\varepsilon / 2+\left(D^{-1 / q_{n}} \cdot B^{H} g^{H}(x)\right)^{q_{n}}<\varepsilon,
\end{aligned}
$$


and this completes the proof.

One may show that if (9) is true and if (17) holds for $D=1$, and if either $\inf _{n} q_{n}>0$ or $\inf _{k} p_{k}>1$, then $A \in\left(l(p), c_{0}(q)\right)$, but that these conditions are not sufficient for $A \in\left(l(p), c_{0}(q)\right)$ if $\inf _{n} q_{n}=0$ and $\inf _{k} p_{k}=1$.

THEOREM 9. Let $q$ be bounded, and let $1<p_{k} \leqq H$ and $p_{k}^{-1}+$ $s_{k}^{-1}=1$ for all $k \in N$. Then $A \in(l(p), c(q))$ if and only if $\sup _{n} \Sigma_{k} \times$ $\left|a_{n, k}\right|^{s} B^{-s_{k}}<\infty$ for some $B>1$ and there exist $\alpha_{1}, \alpha_{2}, \ldots$ such that (11) holds and $\lim _{B} \lim \sup _{n}\left(\Sigma_{k}\left|a_{n, k}-\alpha_{k}\right|^{s_{k}} \cdot D^{s_{k} / q_{n}} \cdot B^{-s_{k}}\right)^{q_{n}}=0$ for all $D \geqq 1$.

Proof. As usual, define $A_{n}$ on $l(p)$ by (13) for each $n \in N$. First let $A \in(l(p)), c(q) \subset\left(l(p), l_{\infty}\right)$; then $\sup _{n} \Sigma_{k}\left|a_{n, k}\right|^{s_{k}} \cdot B^{-s_{k}}<\infty$ for some $B>1$. Also by Theorem 3 there is an $l \in l(p)^{*}$ such that $\mid A_{n}\left(e^{(k)}\right)-$ $\left.l\left(e^{(k)}\right)\right|^{q_{n}} \rightarrow 0(n \rightarrow \infty)$ for each $k$ and such that $\lim _{B} \lim \sup _{n}\left(\| A_{n}\right.$ $\left.l \|_{B}\right)^{q_{n}}=0$. By Lemma 4 we can write $l(x)=\Sigma_{k} \alpha_{k} x_{k}$ on $l(p)$ for some sequence $\left(\alpha_{k}\right) \in l(p)^{\dagger}$, and the necessity now follows using the method of Theorem 8.

For the sufficiency, we show that the conditions of this theorem imply $\Sigma_{k}\left|\alpha_{k}\right|^{s_{k}} \cdot M^{-s_{k}}<\infty$ for some $M>1$; then $l(x) \equiv \Sigma_{k} \alpha_{k} x_{k}$ defines an element of $l(p)^{*}$. We have for suitably large $B$ and $n$

$$
\begin{aligned}
\Sigma_{k}\left|\alpha_{k}\right|^{s_{k}}(2 B)^{-s_{k}} & =\Sigma_{k}\left|\alpha_{k}-a_{n, k}+a_{n, k}\right|^{s_{k}} \cdot(2 B)^{-s_{k}} \\
& \leqq \Sigma_{k} \max \left(\left|a_{n, k}-\alpha_{k}\right|,\left|a_{n, k}\right|\right)^{s_{k}} \cdot B^{-s_{k}} \\
& \leqq \Sigma_{k}\left|a_{n, k}-\alpha_{k}\right|^{s_{k}} \cdot B^{-s_{k}}+\Sigma_{k}\left|a_{n, k}\right|^{s_{k}} \cdot B^{-s_{k}} \\
& \leqq 1+\sup _{n} \Sigma_{k}\left|a_{n, k}\right|^{s_{k}} \cdot B^{-s_{k}}<\infty .
\end{aligned}
$$

Then by Theorem $8,\left(a_{n, k}-\alpha_{k}\right) \in\left(l(p), c_{0}(q)\right)$ whence $\left|A_{n}(x)-l(x)\right|^{q_{n}} \rightarrow 0$ $(n \rightarrow \infty)$ on $l(p)$, and the proof is complete.

We note that $(l(p), c)$ was characterized, for bounded $p$, in the corollary to Theorem 1 of [3].

The conditions for $A \in\left(l(p), l_{\infty}(q),\left(l(p), c_{0}(q)\right)\right.$ or $!(l(p), c(q))$ in the general case $0<p_{k} \leqq \sup p_{k}<\infty$ and $q$ bounded may be obtained by combining the separate cases $0<p_{k} \leqq 1$ and $1<p_{k} \leqq H$ above.

\section{REFERENCES}

1. K. Chandrasekhara, Rao, Matrix transformations of some sequence spaces-II, Glasgow Math. J., 11 (1970), 162-166.

2. V. Ganapathy Iyer, On the space of integral functions-I, J. Indian Math. Soc., (2) 12 (1948), 13-30.

3. C. G. Lascarides and I. J. Maddox, Matrix transformations between some classes of sequences, Proc. Camb. Phil. Soc., 68 (1970), 99-104.

4. I. J. Maddox, Spaces of strongly summable sequences, Quarterly J. Math. Oxford, 
(2) 18 (1967), 345-355.

5. I. J. Maddox, Paranormed sequence spaces generated by infinite matrices, Proc. Camb. Phil. Soc., 64 (1968) 335-340.

6. - Continuous and Köthe-Toeplitz duals of certain sequence spaces, Proc. Camb. Phil. Soc., 65 (1969) 431-435.

7. — , Some properties of paranormed sequence spaces, J. London Math., Soc., (2) 1 (1969), 316-322.

8. W. L. C. Sargent, On some theorems of Hahn, Banach and Steinhaus, J. London Math. Soc., 28 (1953), 438-451.

9. S. Simons, The sequence spaces $l\left(p_{\nu}\right)$ and $m\left(p_{\nu}\right)$, Proc. London Math. Soc., (3) 15 1965), $422-436$.

10. M. A. L. Willey, On sequences of bounded linear functionals with applications to matrix transformations, J. London Math. Soc., (2) 7 (1973), 19-30.

Received August 7, 1973. This paper was written while M. A. L. Willey held a Science Council Research Studentship, and the support of the Council is very greatefully acknowledged.

The QueEn's University of BeLfast 


\section{PACIFIC JOURNAL OF MATHEMATICS}

\section{EDITORS}

RICHARD ARENS (Managing Editor)

University of California

Los Angeles, California 90024

R. A. Beaumont

University of Washington

Seattle, Washington 98105
J. DugundJI

Department of Mathematics

University of Southern California

Los Angeles, California 90007

D. Gilbarg and J. Milgram

Stanford University

Stanford, California 94305

\section{ASSOCIATE EDITORS}

E. F. BECKENBACH

B. H. NeUMANN

F. WOLF

K. YosHIDA

\section{SUPPORTING INSTITUTIONS}

UNIVERSITY OF BRITISH COLUMBIA

CALIFORNIA INSTITUTE OF TECHNOLOGY

UNIVERSITY OF CALIFORNIA

MONTANA STATE UNIVERSITY

UNIVERSITY OF NEVADA

NEW MEXICO STATE UNIVERSITY

OREGON STATE UNIVERSITY

UNIVERSITY OF OREGON

OSAKA UNIVERSITY
UNIVERSITY OF SOUTHERN CALIFORNIA

STANFORD UNIVERSITY

UNIVERSITY OF TOKYO

UNIVERSITY OF UTAH

WASHINGTON STATE UNIVERSITY

UNIVERSITY OF WASHINGTON

$\stackrel{*}{*} \stackrel{*}{*} \stackrel{*}{*}$ AMERICAN MATHEMATICAL SOCIETY




\section{Pacific Journal of Mathematics}

\section{Vol. 53, No. $1 \quad$ March, 1974}

Martin Bartelt, Strongly unique best approximates to a function on a set, and a finite

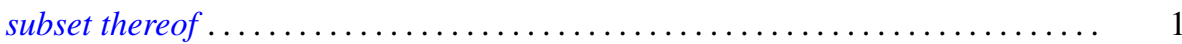

S. J. Bernau, Theorems of Korovkin type for $L_{p}$-spaces $\ldots \ldots \ldots \ldots \ldots \ldots \ldots \ldots \ldots$

S. J. Bernau and Howard E. Lacey, The range of a contractive projection on an

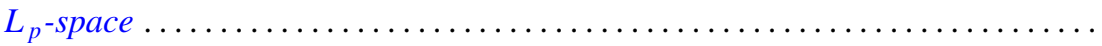

Marilyn Breen, Decomposition theorems for 3-convex subsets of the plane ......... Ronald Elroy Bruck, Jr., A common fixed point theorem for a commuting family of

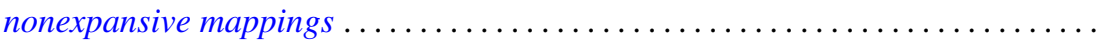

Aiden A. Bruen and J. C. Fisher, Blocking sets and complete $k$-arcs . . . . . . . 73

R. Creighton Buck, Approximation properties of vector valued functions . ......... 85

Mary Rodriguez Embry and Marvin Rosenblum, Spectra, tensor products, and

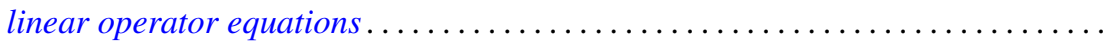

Edward William Formanek, Maximal quotient rings of group rings . . . . . . . . . 109

Barry J. Gardner, Some aspects of T-nilpotence . . . . . . . . . . . . . . . 117

Juan A. Gatica and William A. Kirk, A fixed point theorem for $k$-set-contractions

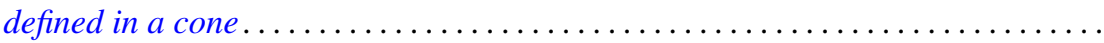

Kenneth R. Goodearl, Localization and splitting in hereditary noetherian prime

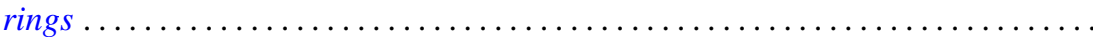

James Victor Herod, Generators for evolution systems with quasi continuous

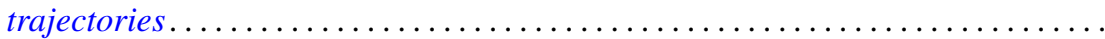

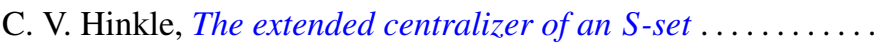

I. Martin (Irving) Isaacs, Lifting Brauer characters of p-solvable groups . . .

Bruce R. Johnson, Generalized Lerch zeta function ...........

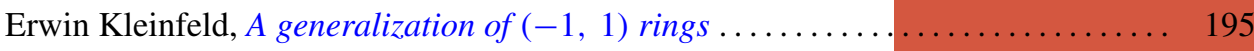

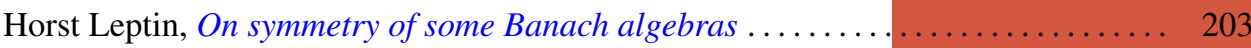

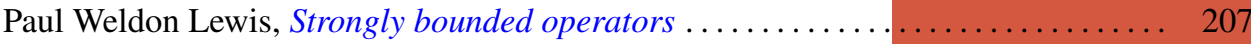

Arthur Larry Lieberman, Spectral distribution of the sum of self-adjoint

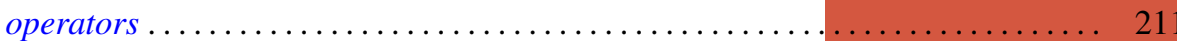

I. J. Maddox and Michael A. L. Willey, Continuous operators on paranormed spaces and matrix transformations

James Dolan Reid, On rings on groups ........................... 229

Richard Miles Schori and James Edward West, Hyperspaces of graphs are Hilbert cubes.

William H. Specht, A factorization theorem for p-constrained groups ...

Robert L Thele, Iterative techniques for approximation of fixed points of certain nonlinear mappings in Banach spaces ...............

Tim Eden Traynor, An elementary proof of the lifting theorem

Charles Irvin Vinsonhaler and William Jennings Wickless, Completely decomposable groups which admit only nilpotent multiplications .

Raymond O’Neil Wells, Jr, Comparison of de Rham and Dolbeault cohomology for

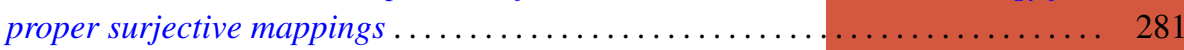

David Lee Wright, The non-minimality of induced central representations . . . . . 301 